\title{
Photodynamic diagnosis of peritoneal metastasis in human pancreatic cancer using 5-aminolevulinic acid during staging laparoscopy
}

\author{
KYOICHI HARADA ${ }^{1}$, YASUTOSHI MURAYAMA ${ }^{1}$, HIDEMASA KUBO ${ }^{1}$, HISATAKA MATSUO ${ }^{1}$, RYO MORIMURA ${ }^{1}$, \\ HISASHI IKOMA ${ }^{1}$, HITOSHI FUJIWARA ${ }^{1}$, KAZUMA OKAMOTO ${ }^{1}$, TOHRU TANAKA ${ }^{2}$ and EIGO OTSUJI ${ }^{1}$ \\ ${ }^{1}$ Division of Digestive Surgery, Department of Surgery, Kyoto Prefectural University of Medicine, \\ Kyoto 602-8566; ${ }^{2}$ SBI Pharmaceuticals Co., Ltd., Izumi Garden Tower 20F, Tokyo 106-6020, Japan
}

Received September 14, 2017; Accepted April 26, 2018

DOI: $10.3892 / \mathrm{ol} .2018 .8732$

\begin{abstract}
Peritoneal metastasis is an important prognostic factor for pancreatic cancer. The present study evaluated the possibility of diagnosing peritoneal metastasis by a photodynamic diagnosis using 5-aminolevulinic acid (5-ALA-PDD).In vitro, protoporphyrin IX(PpIX)accumulation was examined in the AsPC-1-GFP cell line following 5-ALA hydrochloride administration. In vivo, AsPC-1-GFP cells were injected into the peritoneal cavities of mice. Three weeks later 5-ALA hydrochloride was intraperitoneally administered to the mice. The peritoneal nodules were observed under fluorescence excitation. A total of 34 patients were enrolled in the present study who were clinically diagnosed with pancreatic malignancy. 5-ALA hydrochloride was orally administered to the patients prior to surgery. During the operation the abdominal cavity was observed under white light and fluorescence. In vitro and in vivo, it was confirmed that PpIX-induced red fluorescence. In 9 patients peritoneal nodules suspected to be peritoneal metastasis were observed under white light. In 4 of the 9 patients nodules were detected on the basis of the fluorescence images. Fluorescent nodules were histopathologically diagnosed as metastatic. In the present study it was confirmed that 5-ALA-PDD holds promise for the rapid diagnosis of peritoneal metastasis in patients with pancreatic cancer.
\end{abstract}

\section{Introduction}

Pancreatic cancer is a severe disease with a poor 5-year survival rate of $<5 \%$ (1-3). Despite the great strides made in the surgical

Correspondence to: Dr Yasutoshi Murayama, Division of Digestive Surgery, Department of Surgery, Kyoto Prefectural University of Medicine, 465 Kajii-cho, Kyoto 602-8566, Japan E-mail: murayama@koto.kpu-m.ac.jp

Key words: photodynamic diagnosis, 5-aminolevulinic acid, pancreatic cancer, peritoneal metastasis, staging laparoscopy and chemotherapeutic management of pancreatic cancer, the disease continues to have a poor prognosis. Pancreatic cancer has an unfavourable outcome because it is difficult to detect at early stages. Patients are typically diagnosed at a late stage when the cancer has already locally advanced or spread to other parts of the body (4-7). The only potentially curative therapy is surgical resection. However, when patients are diagnosed with pancreatic cancer, more than half are at an unresectable stage and are given chemotherapy, radiation, palliative surgery or supportive care $(8,9)$. Even if patients undergo curative resection, their 5-year survival rates are approximately 15-20\%, with a median survival of 16 to 23 months (10-13).

Peritoneal metastasis is one of the most important prognostic factors for pancreatic cancer. According to the National Comprehensive Cancer Network (NCCN), the presence of peritoneal metastasis is an inoperative factor for pancreatic cancer (14).

Radical surgery is chosen among options including pancreaticoduodenectomy (PD), distal pancreatectomy (DP) or total pancreatectomy, according to the location of the pancreatic cancer. These operations are relatively invasive surgeries (15-17).

It is important to diagnose peritoneal metastasis to avoid unnecessary laparotomy and to determine the appropriate therapy. However, it is difficult to detect small nodules suspected to be peritoneal metastasis during pre-operative imaging examinations, through techniques such as computed tomography (CT) and ${ }^{18} \mathrm{~F}$-fluoro-deoxy-glucose positron emission tomography (FDG-PET). Small lesions can be diagnosed only by intra-operative findings $(9,18)$. Despite the availability of high-resolution CT scans, occult distant metastases are still observed in $11 \%$ of patients during surgery (18).

Sugiura et al have identified recurrent disease (at the local, lymph node, peritoneum, liver and other distant levels) in $76.9 \%$ of pancreatic cancer patients with an R0-resection (curative resection with a negative pathologic margin) (19). In Helsinki University Hospital, in a subgroup of patients with T1-2 disease and an N0 [the Tumour-Node-Metastasis (TNM) classification of the Union for International Cancer Control (UICC)] or R0-resection, the 5-year survival was 49\%, and the 10 -year survival was $31 \%$ (17). Even after an R0-resection, 
some few patients died from recurrence $(12,17,19,20)$. In the R0-resection patient group, the partial cause of recurrence might be the difficulty of intraoperative assessment of small or flat peritoneal metastases. It is necessary to be more precise in detecting peritoneal metastases by intra-operative findings.

Staging laparoscopy has been proposed as a minimally invasive technique to detect radiographically occult intraperitoneal metastatic lesions $(18,21-24)$. However, diagnosis with standard laparoscopy has limitations. Schnelldorfer et al have reported that standard laparoscopy misses the majority of these metastases, thus resulting in a substantial number of patients undergoing a nontherapeutic laparotomy (18).

5 -aminolevulinic acid (5-ALA) is a natural amino acid that is metabolized into photosensitive protoporphyrin IX (PpIX), which accumulates in cancer cells. PpIX emits red (peak wavelength $\sim 635 \mathrm{~nm}$ ) fluorescence when it is excited with blue light (peak wavelength $\sim 405 \mathrm{~nm}$ ), and the fluorescence diagnosis of cancer by using this property is called photodynamic diagnosis (PDD) $(25,26)$. Recently, researchers have reported the usefulness of PDD using 5-ALA (5-ALA-PDD) in the fields of neurosurgery and urology (27-30). Fluorescence cystoscopy has a sensitivity for detection of bladder lesions of $94.2 \%$ and a specificity of $80.0 \%$ (27). We have previously reported the use of 5-ALA-PDD for detection of peritoneal dissemination and lymph node metastasis in patients with gastric or colorectal cancer (31-36).

In the present study, we evaluated the usefulness of 5-ALA-PDD for detecting peritoneal metastasis of pancreatic cancer during staging laparoscopy.

\section{Materials and methods}

Cell line and culture. The human pancreatic adenocarcinoma cell line AsPC-1 (Wako Pure Chemical Industries, Ltd., Osaka, Japan), which was engineered to stably express green fluorescent protein (GFP), was used. AsPC-1-GFP was cultured in RPMI1640 medium supplemented with $10 \%$ foetal bovine serum and $1 \%$ penicillin/streptomycin in tissue culture dishes humidified at $37^{\circ} \mathrm{C}$ in an atmosphere of $95 \%$ air and $5 \%$ carbon dioxide.

In vitro experiments. AsPC-1-GFP $\left(1 \times 10^{6}\right.$ cells $)$ cells were cultured for 3 days. Dishes were washed with PBS and incubated with RPMI-1640 medium with $1 \mathrm{mM}$ 5-ALA hydrochloride (Wako Pure Chemical Industries) for $3 \mathrm{~h}$. Then, we observed the fluorescence of PpIX (excitation, $440 \mathrm{~nm}$; emission, 575-675 nm) and GFP (excitation, $488 \mathrm{~nm}$; emission, 500-560 nm) with an inverted microscope (IX81) equipped with a confocal scanning system (FV1000; both Olympus, Tokyo, Japan).

Animals. Five-week-old-female BALB/c nude mice were used in this study. All in vivo experiments were approved and followed the institutional guidelines of the Kyoto Prefectural University of Medicine (Kyoto, Japan). The mice were housed in plastic cages with stainless steel grid tops in an air-conditioned environment with a 12-h light-dark cycle and had access to food and water ad libitum.

Establishment of the mouse model of peritoneal metastasis and fluorescence observation. An aliquot of $5 \times 10^{6}$
Table I. Patient characteristics $(\mathrm{n}=34)$.

Characteristic

Number of patients

Sex

Male

Female

Age range (median), years

$39-81(70.5)$

Cancer TNM stage ${ }^{a}$

0

IA

0

IB

2

IIA

2

24

IIB

2

III

4

IV

0

${ }^{a}$ UICC 6th TNM classification. UICC, Union for International Cancer Control; TNM, tumour, node and metastasis.

AsPC-1-GFP cells was injected into the peritoneal cavities of mice under general anaesthesia. After 3 weeks, the mice were intraperitoneally injected with 5-ALA hydrochloride at a dose of $250 \mathrm{mg} / \mathrm{kg}$ body weight. Four h after 5-ALA administration, the mice were euthanized, and laparotomy was performed (37). Fluorescence observation was performed with a stereoscopic microscope (SZX16; Olympus) equipped with a colour charge-coupled digital camera (DP73) and a mercury lamp (U-LH100HG; both Olympus). PpIX images (>430 nm; HQ430LP) were acquired by excitation at 405 $\pm 20 \mathrm{~nm}$ (D405/20x; both Chroma Technology Corp., Rockingham, VT, USA), and GFP fluorescence images (595-540 nm; GFPHQ cube) were acquired by excitation at 460 to $480 \mathrm{~nm}$ (GFPHQ cube, both Olympus). The merged image composites were generated with image analysis software (ImageJ 1.45s, National Institutes of Health, Bethesda, MD, USA).

Enrolled patients. Thirty-two patients clinically diagnosed with pancreatic cancer and 2 patients clinically diagnosed with intraductal papillary-mucinous carcinoma (IPMC) were enrolled in the present study. They underwent surgery at the University Hospital, Kyoto Prefectural University of Medicine, between April 2013 and February 2016. Peritoneal metastasis was not detected by pre-operative imaging examinations, such as $\mathrm{CT}$ and FDG-PET.

The present study was approved by the Ethics Committee of Kyoto Prefectural University of Medicine, Kyoto, Japan. The patients provided signed informed consent pre-operatively.

Laparoscopic procedure. 5-ALA hydrochloride (Cosmo Bio Co., Ltd., Tokyo, Japan) was orally administered to patients $3 \mathrm{~h}$ before surgery at a dose of $20 \mathrm{mg}$ per kg body weight $(\leq 1 \mathrm{~g}$ per individual) $(36,37)$. The system used to perform fluorescence laparoscopy in 3 patients was previously described (31). Thirty-one patients were observed with a D-LIGHT C system (Karl Storz GmbH \& Co., Tuttlingen, Germany). 


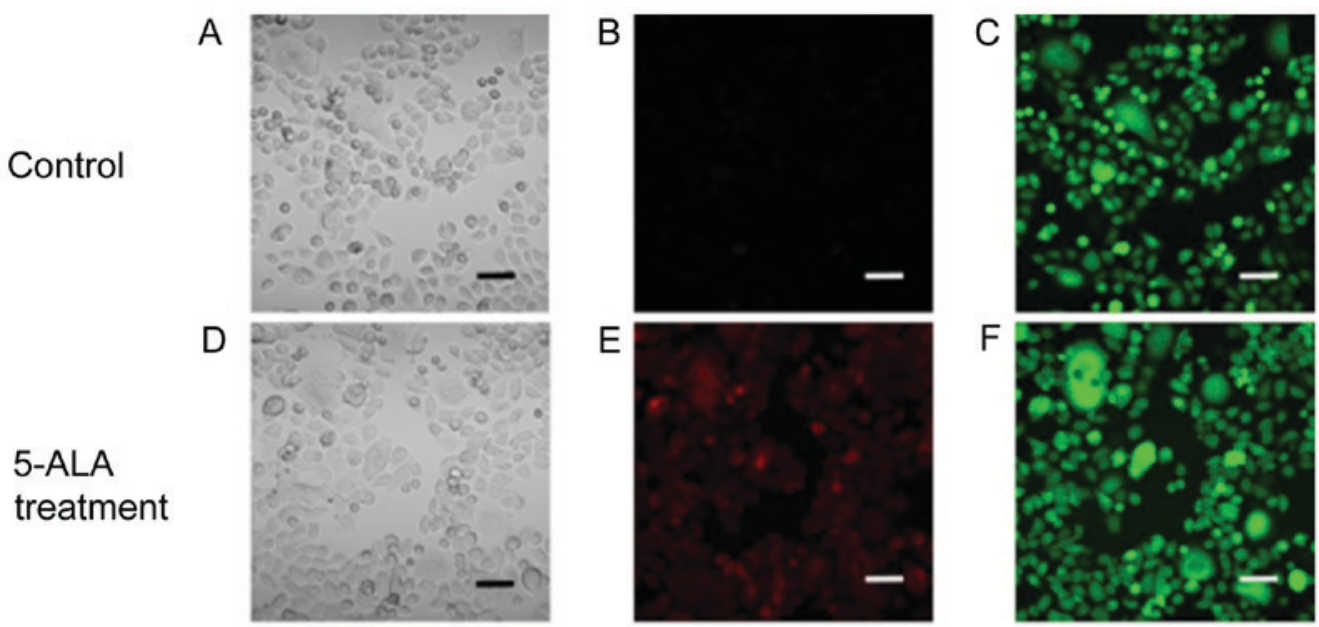

Figure 1. Stereomicroscopic imaging analyses of the human pancreatic cancer cell line AsPC-1-GFP in vitro. (A and D) Imaging under white light, (B and E) fluorescence excitation (excitation, $440 \mathrm{~nm}$; emission, 575-675 nm) and (C and F) excitation, $488 \mathrm{~nm}$; emission, $500-560 \mathrm{~nm}$. Scale bar, $50 \mu \mathrm{m}$. 5-ALA-PDD, 5-aminolevulinic acid.
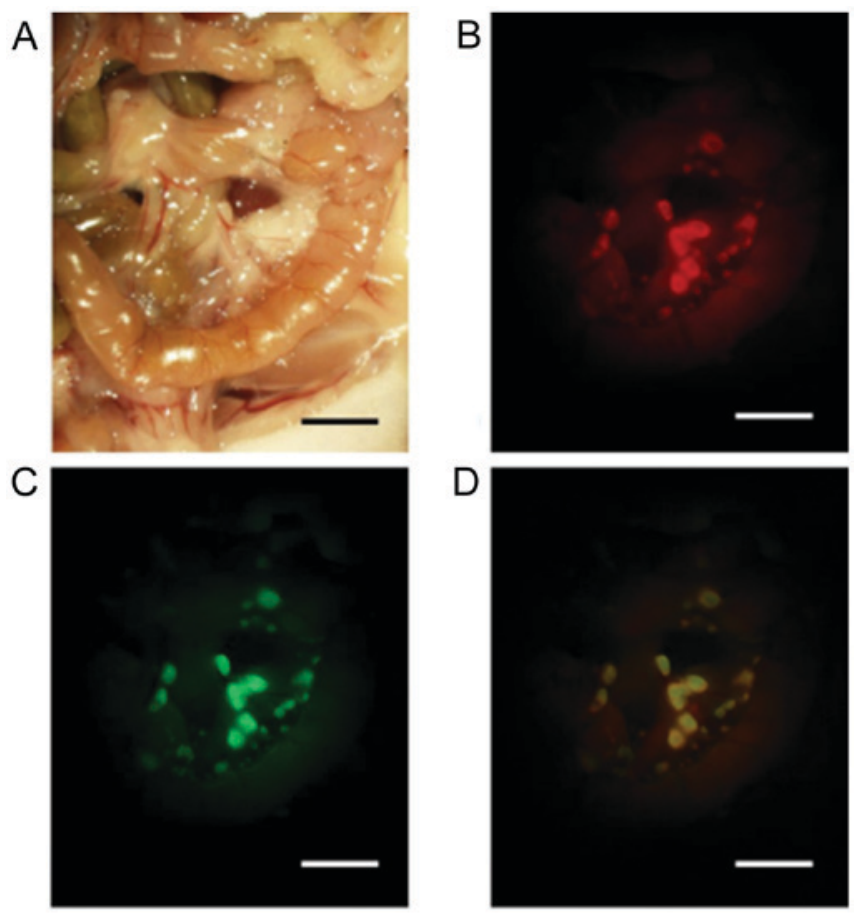

Figure 2. Stereomicroscopic imaging analyses of peritoneal metastasis at the mesentery in a mouse model. (A) Imaging under white light and (B) fluorescence excitation (excitation, $440 \mathrm{~nm}$; emission, 575-675 nm) (C) excitation, 468-480 nm; emission, $495-540 \mathrm{~nm}$. The merged image was generated by ImageJ. (D) Scale bar, $5 \mathrm{~mm}$.

At the beginning of the staging laparoscopy, the abdominal cavity was observed under white light and fluorescence imaging with a long pass filter (>450 nm); images were obtained under excitation with blue light (380-430 nm).

\section{Results}

Stereomicroscopic imaging analyses of pancreatic cancer cell lines in vitro. As shown in Fig. 1, PpIX-induced red fluorescence was observed in the ASPC-1-GFP cells treated with $1 \mathrm{mM}$ 5-ALA hydrochloride. The PpIX-induced red fluorescence matched the observed GFP-induced green fluorescence.
These results indicated that PpIX had accumulated in the human pancreatic cancer cells treated with 5-ALA.

Stereomicroscopic imaging analyses of peritoneal metastasis in a mouse model. To determine whether 5-ALA administration can be used to specifically visualize peritoneal metastasis, a mouse model of peritoneal metastasis was used. Three weeks after intraperitoneal injection of ASPC-1-GFP cells, the peritoneal metastases at the mesentery were visible macroscopically. Although detection of the small nodules of the mesentery was difficult under white light conditions, the small nodules were easily identified in the fluorescence images. The 5-ALA-induced red fluorescent nodules matched the observed GFP-induced green fluorescent nodules (Fig. 2). In our study, peritoneal inspection was performed by counting the nodules by using the same size field of view of the mesentery in five mice (Fig. 3). In the five mice examined, the tumor detection rate using ALA-PDD was higher than that for white light observation (100\%; $184 / 184$ vs. $21.2 \%$; 39/184).

Laparoscopic 5-ALA-PDD of peritoneal metastasis in pancreatic cancer patients. The details of the patient characteristics are summarized in Tables I and II. The patients comprised 19 men and 15 women (median age, 70.5 years; range, 39-81 years) who had been clinically diagnosed with Stage IA-III pancreatic cancer or IPMC (UICC 6th TNM classification). All patients underwent conventional staging laparoscopy and fluorescent observation. In 9 patients, peritoneal nodules suspected to be peritoneal metastasis were observed under white light. In 4 (case 1, 15, 29 and 34) of the 9 patients, nodules were detected in the fluorescence images. All nodules were pathologically diagnosed as peritoneal metastasis (Fig. 4). In the other five cases (case 4, 25, 26, 28 and 33), the nodules that were observed under white light but not under fluorescence excitation were diagnosed as non-malignant by frozen section diagnosis (Fig. 5). The pathological results for cases 4 and 28 indicated fibroadipose tissue. Similarly, the results for case 25 indicated fibrosis 
Table II. Patient characteristics and comparison of the detection of peritoneal metastases under white light and fluorescence excitation.

\begin{tabular}{|c|c|c|c|c|c|c|c|}
\hline \multirow[b]{2}{*}{ Case } & \multirow[b]{2}{*}{$\begin{array}{c}\text { Clinical } \\
\text { diagnosis }\end{array}$} & \multirow[b]{2}{*}{ Operation } & \multirow[b]{2}{*}{$\begin{array}{l}\text { Pathological diagnosis } \\
\text { of specimen }\end{array}$} & \multirow[b]{2}{*}{$\begin{array}{c}\text { TNM } \\
\text { classification }\end{array}$} & \multicolumn{3}{|c|}{ Peritoneal assessment } \\
\hline & & & & & WL & $\mathrm{BL}$ & $\begin{array}{c}\text { Histological diagnosis } \\
\text { of nodule }\end{array}$ \\
\hline 1 & PK & UR & & $\begin{array}{l}\text { T4N0M0 Stage III/ } \\
\text { T4N0M1 Stage IV }\end{array}$ & + & + & $\mathrm{Pm}$ \\
\hline 2 & PK & $\mathrm{PH}$ & $\mathrm{Lm}$ & $\begin{array}{l}\text { T3N0M0 Stage IIA/ } \\
\text { T3N0M1 Stage IV }\end{array}$ & & - & \\
\hline 3 & PK & DP & $\mathrm{CP}$ & T2N0M0 Stage IIA/- & & - & \\
\hline 4 & PK & PD & IDC & $\begin{array}{l}\text { T3N0M0 Stage IIA/ } \\
\text { T3N1M0 Stage IIB }\end{array}$ & + & - & - \\
\hline 5 & PK & PD & IPMC (invasive) & $\begin{array}{l}\text { TNOM0 Stage IIA/ } \\
\text { T3NOM0 Stage IIA }\end{array}$ & & - & \\
\hline 6 & PK & DP & IDC & $\begin{array}{l}\text { T3N0M0 Stage IIA/ } \\
\text { T3N1M0 Stage IIB }\end{array}$ & & - & \\
\hline 7 & PK & PD & IDC & $\begin{array}{l}\text { T3N0M0 Stage IIA/ } \\
\text { T3N1M0 Stage II }\end{array}$ & & - & \\
\hline 8 & PK & DP & IDC & $\begin{array}{l}\text { T3NOM0 Stage IIA/ } \\
\text { T3N0M0 Stage IIA }\end{array}$ & & - & \\
\hline 9 & PK & SL & & $\begin{array}{l}\text { T4N1M0 Stage III/ } \\
\text { T4N1M0 Stage III }\end{array}$ & & - & \\
\hline 10 & PK & UR & & $\begin{array}{l}\text { T3N1M0 Stage IIA/ } \\
\text { T4N1M0 Stage III }\end{array}$ & & - & \\
\hline 11 & PK & SL & & $\begin{array}{l}\text { T3NOM0 Stage IIA/ } \\
\text { T3NOM0 Stage IIA }\end{array}$ & & - & \\
\hline 12 & PK & PD & IDC & $\begin{array}{l}\text { T3N1M0 Stage IIB/ } \\
\text { T3N0M0 Stage IIA }\end{array}$ & & - & \\
\hline 13 & PK & DP & IDC & $\begin{array}{l}\text { T4N0M0 Stage II/ } \\
\text { T3N1M0 Stage IIB }\end{array}$ & & - & \\
\hline 14 & PK & SL & & $\begin{array}{l}\text { T3N0M0 Stage IIA/ } \\
\text { T3NOM0 Stage IIA }\end{array}$ & & - & \\
\hline 15 & PK & UR & & $\begin{array}{l}\text { T3N0M0 Stage IIA/ } \\
\text { T3N0M1 Stage IV }\end{array}$ & + & + & $\mathrm{Pm}$ \\
\hline 16 & PK & DP & In situ & $\begin{array}{l}\text { T1N0M0 Stage IA/ } \\
\text { TisN0M0 Stage } 0\end{array}$ & & - & \\
\hline 17 & PK & PD & In situ & $\begin{array}{l}\text { T3NOM0 Stage IIA/ } \\
\text { TisN0M0 Stage } 0\end{array}$ & & - & \\
\hline 18 & PK & DP & IDC & $\begin{array}{l}\text { T3N0M0 Stage IIA/ } \\
\text { T3N1M0 Stage IIB }\end{array}$ & & - & \\
\hline 19 & IPMC & PD & IPMC & $\begin{array}{l}\text { T1N0M0 Stage IA/ } \\
\text { T1N0M0 Stage IA }\end{array}$ & & - & \\
\hline 20 & PK & PD & IPMC (invasive) & $\begin{array}{l}\text { T2N0M0 Stage IB/ } \\
\text { T2N0M0 Stage IB }\end{array}$ & & - & \\
\hline 21 & PK & PD & IDC & $\begin{array}{l}\text { T3N0M0 Stage IIA/ } \\
\text { T3N1M0 Stage IIB }\end{array}$ & & - & \\
\hline 22 & PK & DP, PH & IDC, HCC & $\begin{array}{l}\text { T3N0M0 Stage IIA/ } \\
\text { T3N1M0 Stage IIB }\end{array}$ & & - & \\
\hline 23 & PK & DP & IDC & $\begin{array}{l}\text { T3N0M0 Stage IIA/ } \\
\text { T3N1M0 Stage IIB }\end{array}$ & & - & \\
\hline 24 & PK & PD & IDC & $\begin{array}{l}\text { T3N1M0 Stage IIB/ } \\
\text { T3N1M0 Stage IIB }\end{array}$ & & - & \\
\hline 25 & PK & DP & IDC & $\begin{array}{l}\text { T3N0M0 Stage IIA/ } \\
\text { T3N1M0 Stage IIB }\end{array}$ & + & - & - \\
\hline
\end{tabular}


Table II. Continued.

\begin{tabular}{|c|c|c|c|c|c|c|c|}
\hline \multirow[b]{2}{*}{ Case } & \multirow[b]{2}{*}{$\begin{array}{l}\text { Clinical } \\
\text { diagnosis }\end{array}$} & \multirow[b]{2}{*}{ Operation } & \multirow[b]{2}{*}{$\begin{array}{l}\text { Pathological diagnosis } \\
\text { of specimen }\end{array}$} & \multirow[b]{2}{*}{$\begin{array}{c}\text { TNM } \\
\text { classification }^{\mathrm{a}}\end{array}$} & \multicolumn{3}{|c|}{ Peritoneal assessment } \\
\hline & & & & & WL & BL & $\begin{array}{l}\text { Histological diagnosis } \\
\text { of nodule }\end{array}$ \\
\hline 26 & PK & DP & IDC & $\begin{array}{l}\text { T3N0M0 Stage IIA/ } \\
\text { T3N0M0 Stage IIA }\end{array}$ & + & - & - \\
\hline 27 & PK & PD & IDC & $\begin{array}{l}\text { T3N0M0 Stage IIA/ } \\
\text { T3N0M0 Stage IIA }\end{array}$ & & - & \\
\hline 28 & PK & PD & IDC & $\begin{array}{l}\text { T3N0M0 Stage IIA/ } \\
\text { T3N0M0 Stage IIA }\end{array}$ & + & - & - \\
\hline 29 & PK & UR & & $\begin{array}{l}\text { T3N0M0 Stage IIA/ } \\
\text { T3N0M1 Stage IV }\end{array}$ & + & + & $\mathrm{Pm}$ \\
\hline 30 & PK & DP & $\mathrm{CP}$ & T3N0M0 Stage IIA/- & & - & \\
\hline 31 & PK & DP & IDC & $\begin{array}{l}\text { T3N0M0 Stage IIA/ } \\
\text { T3N0M0 Stage IIA/ }\end{array}$ & & - & \\
\hline 32 & PK & SL & & $\begin{array}{l}\text { T4N0M0 Stage III/ } \\
\text { T4N0M0 Stage III }\end{array}$ & & - & \\
\hline 33 & IPMC & DP & IPMC (invasive) & $\begin{array}{l}\text { T3N0M0 Stage IIA/ } \\
\text { T3N1M0 Stage IIB }\end{array}$ & + & - & - \\
\hline 34 & PK & UR & & $\begin{array}{l}\text { T3N0M0 Stage IIA/ } \\
\text { T3N0M1 Stage IV }\end{array}$ & + & + & $\mathrm{Pm}$ \\
\hline
\end{tabular}

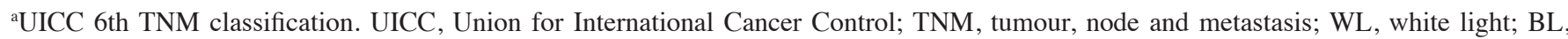
fluorescence light; PK, pancreatic cancer; SL, staging laparoscopy; PD, pancreaticoduodenectomy; DP, distal pancreatectomy; PH, partial hepatectomy; UR, unresectable; Pm, peritoneal metastasis; Lm, liver metastasis; CP, chronic pancreatitis; IDC, invasive ductal carcinoma; IPMC, intraductal papillary-mucinous carcinoma; in situ, adenocarcinoma in situ; HCC, hepatocellular carcinoma.
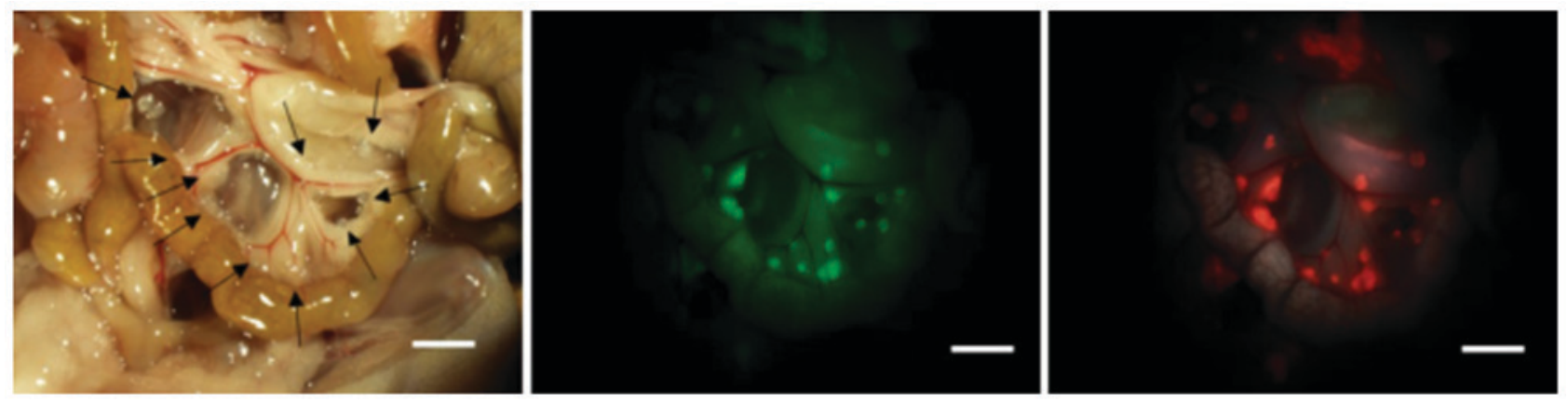

Figure 3. An example of peritoneal metastasis nodules of the mesentery in a mouse. Imaging under white light (left), green fluorescence of green fluorescent protein (middle) and red fluorescence of protoporphyrin IX (right). Recognizable tumor nodules under white light are marked $(\rightarrow$ ). In this case, the tumor detection rate under the white light condition was $52.6 \%$ (10/19), and that of ALA-PDD was 100\% (19/19). Scale bar, 5 mm. ALA-PDD, photodynamic diagnosis using 5-ALA-PDD.

tissue, those for case 26 indicated collagen fibre, and those for case 33 indicated fat and blood vessels.

Four patients (case 9, 11, 14 and 32) were diagnosed with borderline resectable pancreatic cancer by clinical examination and underwent a preoperative staging laparoscopy. These patients did not have inoperative factors and would have been administered neoadjuvant therapy (38). In 5 patients (cases 1, 10, 15, 29 and 34), palliative procedures or an exploratory laparotomy were used because unresectable factors existed (38). In 2 patients (cases 3 and 30), the pathological diagnosis was chronic pancreatitis. No false positives or false negatives were observed in these experiments. None of the enrolled patients experienced any side effects due to 5-ALA hydrochloride administration.

\section{Discussion}

Pancreatic cancer has one of the poorest prognoses of any cancer (1-3). Radical surgery is very invasive (15-17). It is important to diagnose peritoneal metastasis to determine the appropriate therapy and to avoid nontherapeutic laparotomy. However, detection of small nodules 

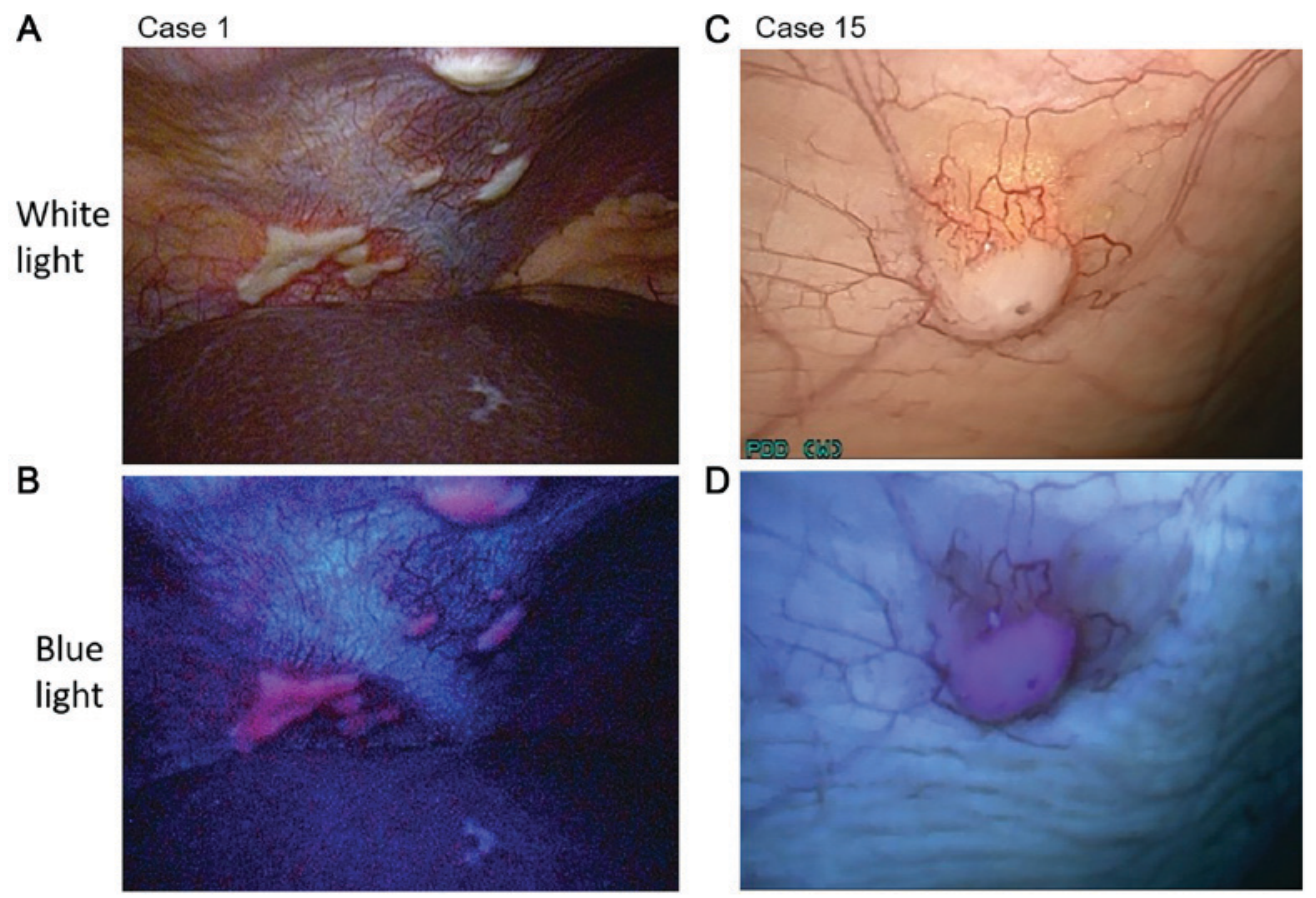

Figure 4. Laparoscopic images of (A and B) case 1 and (C and D) case 15. (A and C) The nodules of the peritoneum under white light conditions. (B and D) Visible red fluorescence under fluorescence light.

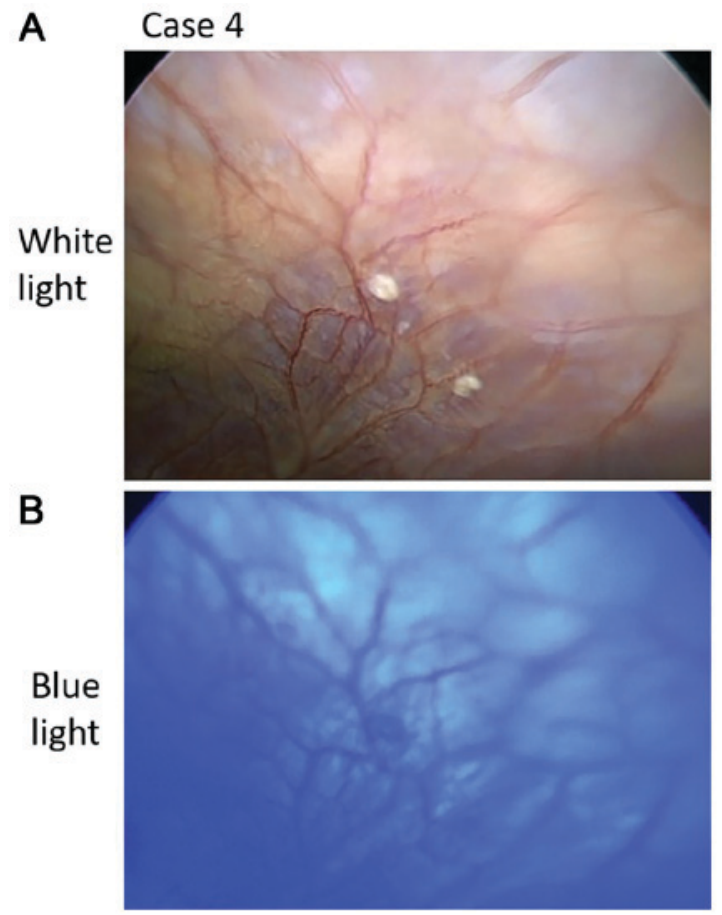

\section{Case 25}
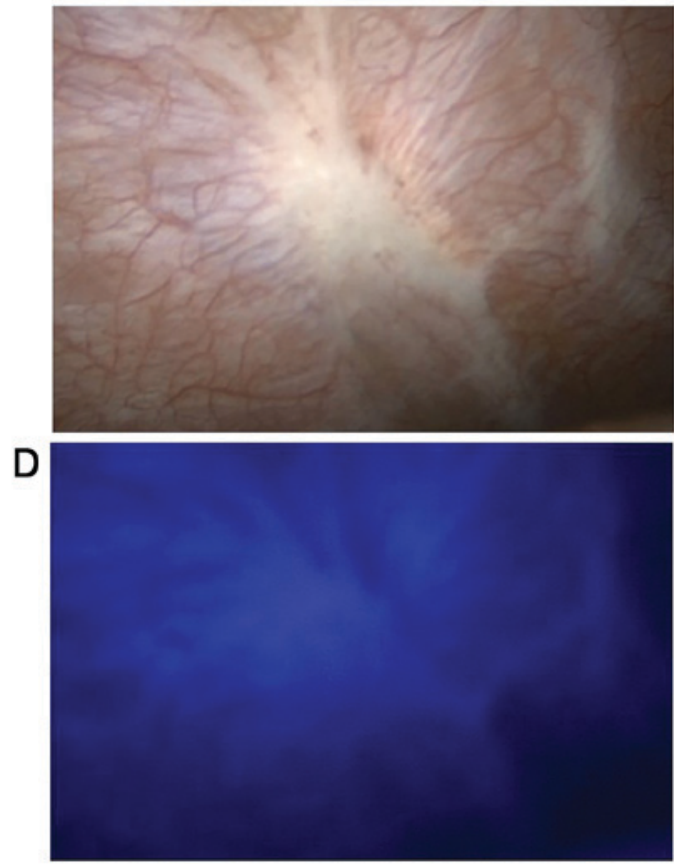

Figure 5. Laparoscopic images of (A and B) case 4 and (C and D) case 25. (A and C) Nodules of the peritoneum under white light conditions. (B and D) Red fluorescence did not appear under fluorescence excitation.

suspected to be peritoneal metastases by pre-operative imaging examinations, such as CT and FDG-PET, is difficult $(9,18)$.

The use of diagnostic laparoscopy for pretherapeutic staging of intraperitoneal tumours has been steadily increasing $(18,22-24)$. The benefits of preoperative staging laparoscopy have been reported for borderline resectable pancreatic cancer $(38,39)$. The complication rate of the staging laparoscopy is very low (24). No acute major complications were found in this study. A major complication that can occur because of treatment delays is the development of port-site metastasis, which has been reported in up to $1 \%$ of diagnostic staging laparoscopies, thus suggesting that this is an uncommon complication $(24,40-42)$. 
Preoperative staging laparoscopy reveals peritoneal and superficial liver metastasis in $\sim 25 \%$ of cases and therefore helps to avoid unnecessary laparotomies. However, unresectable tumours are found in open laparotomy after a staging laparoscopy in $12 \%$ of cases. In an additional $6.8 \%$ of cases, peritoneal metastases are completely missed during the staging laparoscopy $(21,23,24)$.

Recently, researchers have reported the utility of 5-ALA-PDD in the fields of neurosurgery and urology (27-30). 5-ALA has few side effects and is a safe drug that has previously been used to diagnose glioma and bladder cancer (27-30). Although 5-ALA-PDD is a useful method, only a few reports have examined the use 5-ALA-PDD for the diagnosis of peritoneal metastasis in human intra-abdominal malignancy $(23,24,36,43)$. Gahlen et al have reported that the use of fluorescence laparoscopy increases the visualization of intraperitoneal tumours by $17.5 \%$, as compared with white light laparoscopy (23). To our knowledge, the present study is the first systematic report of the use of 5-ALA-PDD during staging laparoscopy for detection of peritoneal metastasis of pancreatic cancer. Our results suggest that the use of this method is applicable for the detection of peritoneal metastasis of pancreatic cancer in real time, which should improve the diagnostic accuracy of peritoneal metastasis.

The 5-ALA-PDD method has some disadvantages. A weak point of this technique is that deep observations are not possible because the penetration of blue light is low in tissues $(32,43)$. Another problem is the undesirable effect of physiological accumulation of PpIX and autofluorescence of the surrounding tissues (36). 5-ALA hydrochloride is administered orally. Therefore, this drug is problematic for patients with symptoms due to gastroduodenal obstruction, such as nausea, vomiting, and difficulty with oral intake. Patients with pancreatic malignancies have a $13-20 \%$ risk of duodenal stenosis (44).

We were not able to experience the persuasive case that is difficult to recognize peritoneal metastasis under white light but easy to recognize under fluorescent observation. We showed that the all nodules suspected of peritoneal metastasis and diagnosed as malignant histopathologically can be identified by the fluorescent observation in realtime. False positive and false negative cases were not observed in our study but would be inevitable if the case series were increased. Negative proof, such as the absence of false negatives, is difficult to provide. Gahlen et al have suggested that open visual inspection and palpation of the entire peritoneal surface are necessary to exclude false negatives; however, it is almost impossible to examine the entire peritoneal surface histopathologically (23). The prognosis should be continuously followed-up.

In the present study, we demonstrated the presence of PpIX-induced red fluorescence in pancreatic cells in vitro and in vivo. In our human study, we observed red fluorescence in peritoneal metastasis of pancreatic cancer by using 5-ALA-PDD during staging laparoscopy. This study indicates that 5-ALA-PDD is useful for detecting peritoneal metastasis during staging laparoscopy in human pancreatic cancer patients.

In conclusion, we confirmed that the use of 5-ALA-PDD during staging laparoscopy is promising for the rapid diagnosis of peritoneal metastasis in pancreatic cancer patients. We suggest that future research assessing the clinical usefulness of this method would be worthwhile.

\section{Acknowledgements}

Not applicable.

\section{Funding}

No funding was received.

\section{Availability of data and materials}

All data generated or analyzed during this study are included in this published article.

\section{Authors' contributions}

YM designed this study. HI and RM performed the pancreatic operations. HM and HK helped perform the experiments. TT advised on the use of 5-ALA within the study and interpreted the data. HF, KO and EO analyzed and interpreted the data. $\mathrm{KH}$ performed the experiments and analyzed the data. All authors read and approved the final manuscript and agree to be accountable for all aspects of the study in ensuring that question related to accuracy or integrity of any part of the work are appropriately investigated and resolved.

\section{Ethics approval and consent to participate}

The present study was approved by the Ethics Committee of Kyoto Prefectural University of Medicine. All study participants proved written informed consent. Animal experimentation within this study was approved by the Institutional Animal Care and Use Committee and performed according to the Animal Experimentation Regulation of Kyoto Prefectural University of Medicine.

\section{Consent for publication}

All participants provided written informed consent for the publication of their data.

\section{Competing interests}

The authors declare that they have no competing interests.

\section{References}

1. Siegel RL, Miller KD and Jemal A: Cancer statistics, 2015. CA Cancer J Clin 65: 5-29, 2015.

2. Tewari M: Pancreatic cancer: A challenge to cure. Indian J Surg 77: 350-357, 2015.

3. Vincent A, Herman J, Schulick R, Hruban RH and Goggins M: Pancreatic cancer. Lancet 378: 607-620, 2011.

4. Gall TM, Tsakok M, Wasan H and Jiao LR: Pancreatic cancer: Current management and treatment strategies. Postgrad Med J 91: 601-607, 2015.

5. Michl P, Pauls S and Gress TM: Evidence-based diagnosis and staging of pancreatic cancer. Best Pract Res Clin Gastroenterol 20: 227-251, 2006

6. Wolfgang CL, Herman JM, Laheru DA, Klein AP, Erdek MA, Fishman EK and Hruban RH: Recent progress in pancreatic cancer. CA Cancer J Clin 63: 318-348, 2013. 
7. Pietryga JA and Morgan DE: Imaging preoperatively for pancreatic adenocarcinoma. J Gastrointest Oncol 6: 343-357, 2015.

8. Cid-Arregui A and Juarez V: Perspectives in the treatment of pancreatic adenocarcinoma. World J Gastroenterol 21: 9297-9316, 2015.

9. Morak MJ, Hermans JJ, Smeenk HG, Renders WM, Nuyttens JJ, Kazemier G and van Eijck CH: Staging for locally advanced pancreatic cancer. Eur J Surg Oncol 35: 963-968, 2009.

10. Baekelandt BM, Hjermstad MJ, Nordby T, Fagerland MW, Kure EH, Heiberg T, Buanes T and Labori KJ: Preoperative cognitive function predicts survival in patients with resectable pancreatic ductal adenocarcinoma. HPB (Oxford) 18: 247-254, 2016.

11. Gillen S, Schuster T, Meyer Zum Büschenfelde C, Friess H and Kleeff J: Preoperative/neoadjuvant therapy in pancreatic cancer: A systematic review and meta-analysis of response and resection percentages. PLoS Med 7: e1000267, 2010.

12. Hartwig W, Hackert T, Hinz U, Gluth A, Bergmann F, Strobel O, Büchler MW and Werner J: Pancreatic cancer surgery in the new millennium: Better prediction of outcome. Ann Surg 254: 311-319, 2011.

13. He J, Ahuja N, Makary MA, Cameron JL, Eckhauser FE, Choti MA, Hruban RH, Pawlik TM and Wolfgang CL: 2564 resected periampullary adenocarcinomas at a single institution: Trends over three decades. HPB (Oxford) 16: 83-90, 2014.

14. Yamaguchi K, Okusaka T, Shimizu K, Furuse J, Ito Y, Hanada K and Shimosegawa T; Committee for revision of clinical guidelines for pancreatic cancer of Japan Pancreas Society: EBM-based Clinical Guidelines for Pancreatic Cancer (2013) issued by the Japan Pancreas Society: A synopsis. Jpn J Clin Oncol 44: 883-888, 2014

15. Lermite E, Sommacale D, Piardi T, Arnaud JP, Sauvanet A, Dejong $\mathrm{CH}$ and Pessaux P: Complications after pancreatic resection: Diagnosis, prevention and management. Clin Res Hepatol Gastroenterol 37: 230-239, 2013

16. Kimura W, Miyata H, Gotoh M, Hirai I, Kenjo A, Kitagawa Y, Shimada M, Baba H, Tomita N, Nakagoe T, et al: A pancreaticoduodenectomy risk model derived from 8575 cases from a national single-race population (Japanese) using a web-based data entry system: The 30-day and in-hospital mortality rates for pancreaticoduodenectomy. Ann Surg 259: 773-780, 2014

17. Seppänen H, Juuti A, Mustonen H, Haapamäki C, Nordling S, Carpelan-Holmström M, Sirén J, Luettges J, Haglund C and Kiviluoto T: The results of pancreatic resections and long-term survival for pancreatic ductal adenocarcinoma: A single-institution experience. Scand J Surg 106: 54-61, 2017.

18. Schnelldorfer T, Gagnon AI, Birkett RT, Reynolds G, Murphy KM and Jenkins RL: Staging laparoscopy in pancreatic cancer: A potential role for advanced laparoscopic techniques. J Am Coll Surg 218: 1201-1206, 2014.

19. Sugiura T, Uesaka K, Mihara K, Sasaki K, Kanemoto H, Mizuno T and Okamura Y: Margin status, recurrence pattern, and prognosis after resection of pancreatic cancer. Surgery 154: 1078-1086, 2013

20. Adham M, Jaeck D, Le Borgne J, Oussoultzouglou E, Chenard-Neu MP, Mosnier JF, Scoazec JY, Mornex F and Partensky C: Long-term survival (5-20 years) after pancreatectomy for pancreatic ductal adenocarcinoma: A series of 30 patients collected from 3 institutions. Pancreas 37: 352-357, 2008.

21. Hemming AW, Nagy AG, Scudamore $\mathrm{CH}$ and Edelmann $\mathrm{K}$ : Laparoscopic staging of intraabdominal malignancy. Surg Endosc 9: 325-328, 1995

22. Mayo SC, Austin DF, Sheppard BC, Mori M, Shipley DK and Billingsley KG: Evolving preoperative evaluation of patients with pancreatic cancer: Does laparoscopy have a role in the current era? J Am Coll Surg 208: 87-95, 2009.

23. Gahlen J, Stern J, Laubach HH, Pietschmann M and Herfarth C: Improving diagnostic staging laparoscopy using intraperitoneal lavage of delta-aminolevulinic acid (ALA) for laparoscopic fluorescence diagnosis. Surgery 126: 469-473, 1999.

24. Zöpf T, Schneider AR, Weickert U, Riemann JF and Arnold JC: Improved preoperative tumor staging by 5 -aminolevulinic acid induced fluorescence laparoscopy. Gastrointest Endose 62: 763-767, 2005

25. Kennedy JC and Pottier RH: Endogenous protoporphyrin IX, a clinically useful photosensitizer for photodynamic therapy. J Photochem Photobiol B 14: 275-292, 1992.

26. Peng Q, Warloe T, Berg K, Moan J, Kongshaug M, Giercksky KE and Nesland JM: 5-Aminolevulinic acid-based photodynamic therapy. Clinical research and future challenges. Cancer 79: 2282-2308, 1997.
27. Kriegmair M, Baumgartner R, Knüchel R, Stepp H, Hofstädter F and Hofstetter A: Detection of early bladder cancer by 5-aminolevulinic acid induced porphyrin fluorescence. J Urol 155: 105-110, 1996.

28. Jichlinski P, Forrer M, Mizeret J, Glanzmann T, Braichotte D, Wagnières G, Zimmer G, Guillou L, Schmidlin F, Graber P, et al: Clinical evaluation of a method for detecting superficial surgical transitional cell carcinoma of the bladder by light-induced fluorescence of protoporphyrin IX following the topical application of 5-aminolevulinic acid: Preliminary results. Lasers Surg Med 20: 402-408, 1997

29. Stummer W, Stocker S, Wagner S, Stepp H, Fritsch C, Goetz C, Goetz AE, Kiefmann R and Reulen HJ: Intraoperative detection of malignant gliomas by 5-aminolevulinic acid-induced porphyrin fluorescence. Neurosurgery 42: 518-526, 1998.

30. Friesen SA, Hjortland GO, Madsen SJ, Hirschberg H, Engebraten O, Nesland JM and Peng Q: 5-Aminolevulinic acid-based photodynamic detection and therapy of brain tumors (review). Int J Oncol 21: 577-582, 2002.

31. Murayama Y, Harada Y, Imaizumi K, Dai P, Nakano K, Okamoto K, Otsuji E and Takamatsu T: Precise detection of lymph node metastases in mouse rectal cancer by using 5-aminolevulinic acid. Int J Cancer 125: 2256-2263, 2009.

32. Murayama Y, Ichikawa D, Koizumi N, Komatsu S, Shiozaki A, Kuriu Y, Ikoma H, Kubota T, Nakanishi M, Harada Y, et al: Staging fluorescence laparoscopy for gastric cancer by using 5-aminolevulinic acid. Anticancer Res 32: 5421-5427, 2012.

33. Hatakeyama T, Murayama Y, Komatsu S, Shiozaki A, Kuriu Y, Ikoma H, Nakanishi M, Ichikawa D, Fujiwara H, Okamoto K, et al: Efficacy of 5-aminolevulinic acid-mediated photodynamic therapy using light-emitting diodes in human colon cancer cells. Oncol Rep 29: 911-916, 2013.

34. Hino H, Murayama Y, Nakanishi M, Inoue K, Nakajima M and Otsuji E: 5-Aminolevulinic acid-mediated photodynamic therapy using light-emitting diodes of different wavelengths in a mouse model of peritoneally disseminated gastric cancer. J Surg Res 185: 119-126, 2013.

35. Koizumi N, Harada Y, Murayama Y, Harada K, Beika M, Yamaoka Y, Dai P, Komatsu S, Kubota T, Ichikawa D, et al: Detection of metastatic lymph nodes using 5-aminolevulinic acid in patients with gastric cancer. Ann Surg Oncol 20: 3541-3548, 2013.

36. Kondo Y, Murayama Y, Konishi H, Morimura R, Komatsu S, Shiozaki A, Kuriu Y, Ikoma H, Kubota T, Nakanishi M, et al: Fluorescent detection of peritoneal metastasis in human colorectal cancer using 5-aminolevulinic acid. Int J Oncol 45: 41-46, 2014

37. Nishimura M, Murayama Y, Harada K, Kamada Y, Morimura R, Ikoma $\mathrm{H}$, Ichikawa D, Fujiwara $\mathrm{H}$, Okamoto $\mathrm{K}$ and Otsuji E: Photodynamic diagnosis of hepatocellular carcinoma using 5-aminolevulinic acid. Anticancer Res 36: 4569-4574, 2016.

38. Hartwig W, Werner J, Jäger D, Debus J and Büchler MW: Improvement of surgical results for pancreatic cancer. Lancet Oncol 14: e476-e485, 2013.

39. Callery MP, Chang KJ, Fishman EK, Talamonti MS, William Traverso L and Linehan DC: Pretreatment assessment of resectable and borderline resectable pancreatic cancer: Expert consensus statement. Ann Surg Oncol 16: 1727-1733, 2009.

40. Pearlstone DB, Mansfield PF, Curley SA, Kumparatana M, Cook P and Feig BW: Laparoscopy in 533 patients with abdominal malignancy. Surgery 125: 67-72, 1999.

41. Shoup M, Brennan MF, Karpeh MS, Gillern SM, McMahon RL and Conlon KC: Port site metastasis after diagnostic laparoscopy for upper gastrointestinal tract malignancies: An uncommon entity. Ann Surg Oncol 9: 632-636, 2002.

42. Reymond MA, Schneider C, Kastl S, Hohenberger W and Köckerling F: The pathogenesis of port-site recurrences. J Gastrointest Surg 2: 406-414, 1998.

43. Kishi K, Fujiwara Y, Yano M, Inoue M, Miyashiro I, Motoori M, Shingai T, Gotoh K, Takahashi H, Noura S, et al: Staging laparoscopy using ALA-mediated photodynamic diagnosis improves the detection of peritoneal metastases in advanced gastric cancer. J Surg Oncol 106: 294-298, 2012.

44. Conio M, Demarquay JF, De Luca L, Marchi S and Dumas R: Endoscopic treatment of pancreatico-biliary malignancies. Crit Rev Oncol Hematol 37: 127-135, 2001.

This work is licensed under a Creative Commons Attribution-NonCommercial-NoDerivatives 4.0 International (CC BY-NC-ND 4.0) License. 